\title{
An intergenerational singing group: $A$ Community music therapy qualitative research project and graduate student mentoring initiative
}

\author{
Guylaine Vaillancourt $^{1 *}$, Danna Da Costa ${ }^{2}$, Evie (Yi) Han ${ }^{3}$, Gloria Lipski ${ }^{4}$ \\ 1 Concordia University, Montreal, QC, Canada \\ 2 Private Practice, Cambridge, ON, Canada \\ 3 Fondation Dr. Julien, Montreal, QC, Canada \\ 4 Music Therapy Center, Toronto, ON, Canada \\ *g.vaillancourt@concordia.ca
}

Received: 16 March 2016 ; Accepted: 19 September 2017 ; Published: 1 March 2018

Editor: Daphne Rickson Reviewers: Helen Oosthuizen, Lucy Bolger

\begin{abstract}
This study describes the implementation and investigation of a community music therapy (COMT) intergenerational singing group. Participants were a non-clinical group of adults aged 20 to 65 years old. Weekly sessions were held over a 10-week period at a community art studio in a lower-income neighborhood within a large Canadian urban city. Participants reported experiencing increased self-expression, a sense of accomplishment, improved respiration, and feelings of general well-being. They developed new relationships and social and community networks, however participants mentioned limitations regarding the sustainability of this community development. They also indicated challenges with the multilingual repertoire. Three professional music therapy graduate students, acting as co-researchers, were introduced to and mentored in implementing community music therapy practice and research. Potential implications and recommendations for further research are discussed.
\end{abstract}

Keywords: Key words: Community music therapy, intergenerational, singing group, community, graduate students

\section{Introduction}

Community music therapy (CoMT) is a social music approach that promotes social inclusion, wellbeing, and a sense of belonging by resourcing clinical and marginalized populations to music within their communities (Ansdell, 2002; Pavlicevic \& Ansdell, 2004; Stige, Ansdell, Elefant, \& Pavlicevic, 2010; Stige \& Aarø, 2012; Vaillancourt, 2012). While international CoMT research has included children, youth, and adults living with special needs or precarious social conditions (Oosthuizen, Fouché, \& Torrance, 2007; Stewart, 2004; Zharinova-Sanderson, 2004), Canadian research is still limited (Baines, 2003; Bird, 1998; Curtis, 2012,, 2015; Curtis \& Vaillancourt, 2012; Curtis \& Mercado, 2004; Snow, Snow, \& D’Amico, 2008; Vaillancourt, 2009; Young, 2009), and a non-clinical population has not been studied. 
Meanwhile, the benefits of the everyday uses of music to support health and wellbeing are getting more academic attention outside of music therapy as well (Bailey \& Davidson, 2003; Batt-Rawden, Trythall, \& DeNora, 2007). The therapeutic properties of music and its potential to improve health, to develop community, and to foster personal cultural expression are being recognised (Bailey \& Davidson, 2003). When it comes to singing in particular, participation in a choir can benefit social, emotional, and mental well-being (Bailey \& Davidson, 2003); vocal exercises and singing can address social, communicational, and physical needs (Fogg \& Talmage, 2011); choral singing can improve mood, health, and wellbeing in the general population (Talmage, Ludlam, Leão, Fogg-Rogers, \& Purdy, 2013); and music can foster emotional awareness, social and spiritual connection, and social competency (Ruud, 2004).

\section{Benefits of Singing}

\section{Psychological benefits of singing}

Bailey and Davidson (2003) found that participants who lived on the street felt that participating in a choir improved their self-esteem, helped them distance themselves from daily problems, and gave them the opportunity to express long-time repressed emotions. According to Bailey and Davidson (2007), singing enables "emotional release, physical arousal, social communion; [and] perhaps it also offers a personal sense of transformation: a shift of the sense of what you experience" (pp. 60-61). ChineseAustralian adults reported that they experienced enjoyment, pleasure, and relaxation when participating in a choir, which translated into improved emotional well-being (Li \& Southcott, 2012). The participants eagerly anticipated their group, which gave them a sense of belonging and purpose.

\section{Social benefits of singing.}

Singing experiences can develop participants' sense of belonging, community, connection, relationship formation and confidence. Regardless of previous singing experience, shared emotional experiences like group singing can lead to group cohesion, a sense of community and connection to others, social expression and a sense of accomplishment (Clift \& Hancox, 2001; Young, 2009). In another study, participants report increased confidence, positive reminiscence, feelings of "instant community", building relationships, making connections, and in the context of an intergenerational singing curriculum, enjoyment of seeing the younger generation (Beynon, Heydon, O'Neill, Zhang, \& Cocker 2013). "Belonging" was also an important theme for a group of older Chinese Australians (Li \& Southcott, 2012):

Being in a group with shared understandings helps members overcome feelings of isolation and loneliness. The weekly rehearsal becomes a social gathering that engenders positive and transformative experiences. When asked why they joined the group, participants responded that forming relationships with others was a strong motivation. (p.67)

Additionally, research has shown that participation in group singing can influence social change and agency within communities. Sattler's (2013) ethnographic study investigating the contribution of music ensemble programs to socio-cultural development in Australia, Canada, and the United States found that adult learning communities involving music can have a role in community social change. Moreover, choir participants living with neurological conditions noted an increased sense of confidence, which counteracted feelings of being stigmatized (Fogg \& Talmage, 2011). The literature also points to the impact of musical participation on the individual's relationship and agency within community and culture, namely that it can bridge social barriers and foster community wellness. Batt-Rawden, Trythall, \& De Nora (2007) suggested that musicking:

...engenders self-awareness, may retrieve fond memories or "happy times" and memories of self as a more capable agent; provides resources for converting music recipients to music 
actors; heightened and renewed forms of agency; [provides] feelings of self-recovery, selfchange, pleasure, connection to others, new lifestyle patterns, and many other means of enhancing well-being or "wellness." (p. 77)

\section{Physiological benefits of singing}

Active participation in singing leads to increased immunoglobulin A (sIgA) and decreased cortisol, which could indicate improvement in immune system functioning (Bailey \& Davidson, 2007). Stacy, Brittain, and Kerr (2002) advanced that singing can affect pulmonary functions such as breathing, muscle tension, posture, and respiratory symptoms. They also found links between singing and emotional and spiritual states, and their influences on the sympathetic nervous system and brain functioning. Stacy et al. (2002) reported that there were numerous variables associated with being music participants and listeners and that the social, psychological, and physiological aspects of being in the music are often intertwined. They found that music can be relaxing; reduce anxiety and depression; elicit different feelings (i.e. relaxation, anger, etc.); and elicit strong “...physical reactions, perception (hearing, seeing), changes of attitudes, emotion and feelings, transcendent aspects (spiritual, religious), and personal development (such as increased self-confidence)" (p. 157). A group of adults living with cancer experienced enhanced body awareness, relaxation, motivation, and physical energy levels (Young, 2009). Singing is also reported to induce endorphin secretion, pain reduction, better oxygenation of the blood, and breathing (Parker, 1999).

\section{Music and Intergenerational Groups}

The reported benefits of singing groups also apply to intergenerational groups. Beynon, Heydon, O'Neill, Zhang, and Cocker (2013) drew on Ayala, Hewson, Bray, Jones, and Hartley's (2007) work to define an intergenerational singing program as "...the purposeful bringing together of different generations for the teaching, learning, and sharing of singing in a 'mutually beneficial' fashion" (p. 5). Belgrave (2012) reported that programs involving intergenerational groups and music are attractive because music is already a part of daily life, either through listening, singing, and/or making music. Daykin (2007) argued that we are all influenced by "cultural notions of aesthetics and music scripts" that influence how we respond to music and perceive health (p. 96). Darrow, Johnson, Ollengerger, and Meeker Miller (2001) showed that intergenerational programming breaches set boundaries. Learning that depression, loneliness, and fearfulness for the future are human experiences that occur at every age, was mutually beneficial in creating empathy and understanding.

Most studies of intergenerational choirs involve young children, students, and senior citizens. In these cases, intergenerational groups present an opportunity for the musical experience, either through participating, observing or listening, to contribute to dissolving stereotypes and negative attitudes (Beynon et al., 2013; Darrow et al., 2001). Making music together can serve as an equalizer between different age groups (Beynon et al., 2013). "It seems possible that music, along with the experience of age and the enthusiasm of youth, can help to bridge the generation gap - not just for the participants, but also for those persons exposed to such groups" (Darrow et al., 2001, p. 49). Cusicanqui and Salmon (2005) studied a joint group of residential seniors and elementary school children attending a dropout-prevention program. Both age groups benefited from the relationships formed, particularly through a reduction in feelings of isolation and improved feelings of being involved in the community. Joy was experienced by singing together. Similarly, Belgrave (2012) found that older adults valued interactions from a music-based intergenerational community program reporting that the combination of being in contact with the younger generation, the quality of the interactions, and the duration of the program provided an occasion to develop friendships among people of various ages. The researchers concluded that, “... interactions assist individuals from multiple generations to see that there are similarities among all generations" (Belgrave, 2012, p. 8). Similarly Conway and Hodgman (2008) exam- 
ined and described the experiences of college and community choir members in a collaborative intergenerational performance project finding that participants developed a greater level of respect for each other through their mutual experiences of singing together.

\section{Community Music Therapy}

Community music therapy (CoMT) appears well suited to theoretically frame intergenerational singing groups because of its ability to bridge groups of individuals with various interests and needs (Stige \& Aarø, 2012). According to Stige (2003),

Community Music Therapy as an area of professional practice is situated health musicking in a community, as a planned process of collaboration between client and therapist with a specific focus upon promotion of sociocultural and communal change through a participatory approach where music as ecology of performed relationships is used in non-clinical and inclusive settings. (p. 254)

CoMT therefore encompasses diverse perspectives, practices, and approaches, even being described as "an anti-model that encourages therapists to resist one-size fits allanywhere models (of any kind), and instead to follow where the needs of the clients, contexts and music leads" (Ansdell, 2004, p. 21).

The importance of paying attention to wider cultural contexts and meanings of music is emphasized within the approach defined as CoMT (Ansdell, 2004; Pavlicevic and Ansdell, 2004; Rudd, 2004; Stige and Aarø, 2012) and by other authors (Daykin, 2007), especially when involving public performance (Ruud, 2004). Ansdell recommended that music therapists explore specific questions pertaining to their identities and roles, sites and boundaries, aims and means, and assumptions and attitudes in order to orient their CoMT practice. Stige and Aarø (2012) suggested "the main focus is promotion of health and prevention of problems rather than curative interventions" ( $\mathrm{p}$. 23) which makes the "therapy" terminology not necessarily accurate. Elefant (2010) studied the merging of two choirs, one comprised of adults with several physical handicaps and the other of individuals with intellectual disabilities. The participatory action research process helped empower group members, building self-esteem and self-determination, and "tapping into their strengths which resulted in mutual collaboration" (p. 206). Stige (2010) also described CoMT work with a senior choir who had been together for more than two decades. Participants saw themselves as healthy despite many having difficulties associated with age, experience of loss (e.g., loss of cognitive functioning, memory challenges, loss of mobility/physical capacity, bereavement, and reduction of their social networks). Stige concluded that the choir encouraged "mutual care as each person's interest for the other's weal and woe is particularly relevant for a senior choir where the singers have sustained a strong interest for music despite their aging condition" (p. 274).

Although the current literature on community, intergeneration and singing demonstrates benefits in social, psychological, and physical domains, specific research on community music therapy singing groups with non-clinical populations is still limited (Curtis, 2015). Music therapists have skills and competencies to expand CoMT approaches to various groups that could improve the global health and well-being of individuals in a cultural and social context. The current study contributes to this expansion by focusing on intergenerational singing groups.

\section{Methodology}

The chosen methodology of this study was a qualitative phenomenological participatory inquiry that sought to involve and capture the essence of the participants' experiences. Three music therapy graduate students took the role of participant co-researchers. Singing group participants had an active role in contributing with song choices throughout the project. The co-researchers worked together to develop the sessions based on the pre-interviews and their weekly observations of participants. They 
contributed to every step of the research process of literature review, recruitment, group preparation, data collection and analysis, etc. The project was guided by the research question: What is the experience of participating in an intergenerational community music therapy singing group?

\section{Participants}

In this study, the singing group has been defined as 'a group of people meeting to develop community connections through music and singing'. Participants were 13 adult women of various ages who met at an affiliated university's community art studio, for 10 weekly hour and a half long group singing sessions. Seven participants including the co-researchers were in their 20 s and 30s and the remaining six women and primary researcher were in their late 50s and 60s. Participants were recruited from specific neighbourhood high schools, senior citizens' and choir organizations, where bilingual recruitment advertisements were disseminated in poster form, as well as through email. Participants came from English-speaking and French-speaking Canada, and Francophone Europe. Six identified English as their primary language while seven primarily spoke French but most could communicate functionally in both languages. Some participants interrupted their attendance: three participants returned to their country of origin and three participants left due to health issues. The group started with 13 participants as one person cancelled her participation. The project progressed with a core group of approximately four to six participants remaining until the end of the program.

\section{Procedures}

The research has the approval of the University Human Research Ethics Committee (UHREC). All participants gave informed consent to be involved in the research. They were also provided with a list of counselling resources at the beginning of the research in case they had the desire to seek counselling confidentially outside of group session times.

An initial 1-hour pre-group interview explored their musical experiences and preferences, group singing background, and expectations for the group. Later, a post-group interview included questions regarding the participants' personal reflections, experiences, and the potential impact of the group on future involvement in their own community once the project was completed.

During the first group session, co-researchers and participants introduced themselves, the research purposes and procedures were explained, and questions were answered. Each group started with the primary researcher and three co-researchers arriving early to set up the recording equipment, keyboard, and seating, and to review the program for the day. Participants came in gradually and were welcomed while a co-researcher played background piano to create a comfortable atmosphere. Light refreshments were provided because the group took place in late afternoon, following work for some participants. One of the co-researchers conducted a vocal and physical warm-up while another accompanied on the keyboard. The facilitated deep breathing exercises created a calm, grounded, trusting, and motivated atmosphere. The primary researcher and co-researchers alternately led a welcome song, in various languages, with keyboard accompaniment. Lyrics were presented on a board. Each participant had their own song book compiled from a list of their favourite repertoire. New songs were added to the binder from suggestions made during weekly discussions. Some participants asked to be given the musical scores, which they received as sheet music by email.

During the sessions, participants were offered musical guidance and encouragement whenever needed to help them feel at ease with each other. The co-researchers used their music therapy skills to facilitate the group and create a safe space. They were available to offer any necessary emotional support in case participants felt discomfort as a result of unexpected emotional responses to the music or lyrics, self-consciousness in relation to singing with others, or self-consciousness in relation to participant self- 
perception of vocal abilities and so on. Participants were encouraged to participate at a level they felt comfortable with, so that an atmosphere of trust, openness, and safety was established. Strategies were put in place for two participants who had previously acquired hearing loss, such as choosing a seating location that maximized their ability to hear. The majority of participants were sensitive to loud sounds and had developed strategies in order to avoid them.

Approximately 6-8 songs from English, French, Spanish, and Hebrew repertoire were sung each week, mostly in unison, sometimes harmonized or in canon. Some songs were repeated from week to week, while one or two new songs were introduced every session. The midway break provided an opportunity for participants to socialize with each other. The group often ended with a canon or the singing of an uplifting closing song, while standing and moving to the music. Following the session, the coresearchers gathered to share observations and to plan for the next session.

\section{Data Collection}

Data from pre and post interviews were audio recorded and the group singing sessions were audio-video recorded. A session observation grid was designed to examine time, situation, occurrences, and interpretations for each group session. Literature was also used as a data source.

\section{Data Analysis}

Interviews were transcribed and translated from French to English as needed, by the primary researcher. Video recordings were reviewed and coded separately by two coresearchers who then met to collaboratively compile them. All electronic data were safely stored on a password protected computer. Data were analysed using Neuman's (2011) coding system, involving a process of open, axial, and selective coding, to determine the main themes in interviews and written observations of videos. Open codes were condensed, categorized, and thematically analyzed into axial codes. Selectively coded literature categories were determined from the axially coded data.

\section{Findings}

\section{Musical Interests and Expectations of Singing Group Members}

The pre-group individual interviews demonstrated that the primary motivation for participants to take part in an intergenerational singing group was the love of singing. Some were looking for a choir. Ten had singing experience while three had never experienced group singing. Themes such as, "the joy of singing, beauty, harmony, the pleasure of music, learning music through a group, meeting people, connecting with other cultures and ages, being part of a group, staying young, self- accomplishment, and activity as a retired person," were mentioned at the beginning of the project.

The participants had experience singing in settings such as church, temple, school, the community, and during music therapy training, in a wide range of jazz, popular, gospel, classical, sacred, and religious styles. One participant, who had never been part of a choir, was told not to sing when she was younger because of the way her voice was perceived, a memory that was still vivid.

Of the 13 group members, eight had a musical background and had trained on a primary musical instrument. Some of them had performed in public with an ensemble, orchestra, congregation, rock band, school band, or choir. Some participants expressed that they liked to sing with the radio, during musical family gatherings, with children, or karaoke style in their home, at a bar, or at a community centre. The majority of the participants mentioned that they had attended musical events in the community, such as concerts (popular, classical, rock, jazz, etc.) and festivals, with a few participants stating that they had had a more active attendance in the past than at the time of the 
study. The high cost of concerts was mentioned as a barrier to participating in these types of cultural activities.

Although most participants liked "all types of music," all had several preferred styles of music. Individuals' least preferred style/genre of music was sometimes in conflict with other participants' preferred style/genre. This was taken into account when selecting songs for the group. Languages of preferred music differed with an equal division of French and English songs, as well as some songs sung in Hebrew and Spanish.

\section{Previous Community Involvement}

Ten out of the thirteen women had been members of organizations, community projects, teams/clubs, and volunteering/leisure. Organizations included a community women's centre, a children's show organization, an artistic intergenerational association, and a social justice organization. Community projects included an international community project with children and international environmental projects. Involvement in teams and clubs included participation in musical theatre, sporting events, outdoor clubs, collective kitchens, and a community art studio. Lastly, volunteering/ leisure community participation included volunteering at a theatre, singing in a long term care programme, and working on audio books.

Some of the women reported engaging in community activities that involved music. Moreover, some reported having had positive experiences while singing with other generations, for instance in high schools, as teenagers, during karaoke at a community center, at community centers, in choirs, and among family. One person reported that it was "wonderful, we formed friendships with other generations, forgot the age, and saw who the person was, felt a real support."

\section{Connecting through Singing}

The data from session observations showed that initially participants seemed a little anxious, expressing nervousness, laughter, smiling, shyness, and apprehension. One person confessed in the interview that "the first meeting in a large group is more intimidating" and similarly for another participant, she felt "easily emotional, shy, and ashamed" as she did not like receiving too much attention. One woman, who suggested she is timid, expressed that she tried to sing "well" at the beginning and to adapt to the repertoire and tonality. She gained more confidence with time and added that it was a place for self-care. Others went through a similar process of adjustment.

People became increasingly relaxed and open as the group progressed. The warmup appeared to be a new experience for many, but their observed body language indicated that they began to relax throughout the process. Some members felt a need to transition slowly into the group context, while others welcomed the social interaction right away and felt at ease quickly. Participants gradually shared their thoughts with the group more spontaneously. It was as if the act of learning something new together facilitated social interactions, and people's personalities came out more naturally. Humour was often used as a way to relieve the tension. Sitting in a circle made participants more aware of each other, and made their interactions more personal, responsive, relational, and invested than they might be in a traditional choir.

Dependence on lyrics seemed to decrease over time and coincided with an increase in confidence and vocal projection. Vocal sections seemed to create small pockets of connection between two or three group members. A sense of unity amongst each small grouping developed; each group seemed to see other groups as a small unit as well, rather than as individuals.

\section{Impact of Songs}

One of the songs, "Hallelujah" by Leonard Cohen, had a unifying and calming nature, which stimulated an exchange of knowledge and ideas that originated from members' life experiences outside of the group, and which felt like a demonstration of communi- 
ty building from the outside-in. Calming feelings and rocking motions were observed in session recordings, as well as soft and blended voices. Many members seemed to feel comforted by the music. There was a sense of stability created by the voices and it seemed that the participants all felt quite safe.

A song that brought spontaneity and joy was "Oh Happy Day"; the group danced and moved to the song, cheering, clapping, and interacting. Participants were observed putting down their song binders and looking towards the leader and each other instead. The focal point for members shifted from internal to external and allowed for the possibility of more group cohesion. Participants started to know each other and to share more about themselves. The concentration level in a smaller group led to powerful music making. There was laughter sometimes at the challenge of keeping together musically. Participants became more musically cohesive with spontaneous harmonies and organic musical moments.

Other songs increased energy level, such as songs by The Beatles. Participants appeared comfortable with the lyrics and melody, especially during the chorus, and they were seen taking the opportunity to make non-verbal connections. Music seemed to act as a container for normal interaction. The division of the group into two singing parts may have created a situation where interaction between participants was unavoidable and therefore facilitated. Energy and willingness to learn was felt from all participants, perhaps fostering feelings of unity because everyone was learning a new song together.

A sense of personal and group accomplishment; pride and pleasure resonated amongst the participants. The use of the keyboard seemed to have become a part of the group. One woman disclosed to everyone that this was the first time she sang in front of other people. This sharing gave the song new meaning for this group in particular by creating an association to the song through a fellow group member.

Some musical choices were more successful than others for participants, who sang either more freely or with more hesitation depending on the song. There was more connection observed through smiling, visual exchanges, body movements, and body percussion when songs were more challenging to sing. In parallel, there were more musical and vocal connections (feelings of oneness in the music) when the song felt easier for the group.

According to one co-researcher, "Human connections appeared and were enhanced by the containment of music - imitation of dance moments from many participants their sense or need to create unity or to be unified in their songs." Participants' singing voices also became louder and stronger, especially within the context of singing in canon. While singing in cannon, everyone sang the same part, in unison for the first round and had staggered timing in subsequent rounds; participants could feel secure in finding a part they could sing comfortably. When learning multiple parts of a song, a high level of group investment and interest were perceived. During the last two sessions participants seemed unified and able to bear the silence while together (not an easy task) and to focus together on the breath.

\section{Session Structure and Ambiance}

The post singing group interviews brought rich and diverse comments from the participants and co-researchers. The structure of the singing group felt free and pleasurable to participants. The warm-ups that helped "break the ice" before singing were appreciated. Some participants mentioned that the co-researchers had different ways of teaching songs, which helped them to engage with the group in various ways. They felt it brought a new: "energy of learning" and that "it was special to see students spread [their] wings." One woman shared that on a physical level, she increased her singing skills and her breathing had improved. Similarly, one participant felt that all senses were involved through the arts. The presence of the co-researchers was appreciated and one participant remarked approvingly about how they were "smiling, warm, participating, passionate, natural" and how they created connections with participants. They were like a "trio" who created a welcoming space. 
The approach and environment were meaningful for participants, as they felt a sense of flexibility, simplicity, conviviality, and that they were being listened to by the co-researchers. They described the community art studio, with its walls decorated with artwork and beautiful atmosphere, as a relational space for mutual aid, gathering, and discussion; it felt like a fitting place and context to hold a singing group. Furthermore, the set-up of a circle around the piano was also inviting for participants. The sense of undemanding atmosphere was mentioned by a few participants as contributing to the pleasure of the group, which they experienced through sharing together in an atmosphere of friendship. Participants named enjoyable positive group elements: "mix of cultures, ages, the inclusion, the freedom, the ambiance, the pleasure, and a time for joy." Another participant mentioned that the cross-age group factors, each person's background, the decrease in apprehension from the group, and the guidance to "just do whatever and enjoy" brought about a feeling of freedom.

Participants shared that the group was a place to experiment, create, and be part of a "community" through the singing group. One participant felt a desire to share with others and said the breaks were a good opportunity to exchange resources and to develop their network. One person discovered people who were “ ... pro-active, very human, friendly ... "; there were people similar to her, so this person felt safe within the group. Another participant said that the group was a confirmation for her that these types of experiences have an effect, and another stated that " ... singing brings community, sharing songs and voices ... ,"while another participant added, “ ... how simple to create community." Also, the sense of community created cohesion and the development of new ongoing relationships as participants could "make new friends, gathering after the group end...exchanging phone numbers." Some members felt that they had become more at ease with meeting people in other contexts outside of the group.

Other comments referred to the pleasure felt by retired women upon seeing each other, feeling spiritually "in the present moment" and not taking themselves too seriously. Comments arose such as, "I went back to laughing and singing freely," and "It felt enriching and the group helped me to come out of isolation and create new relationships." Some mentioned feelings of accomplishment. One participant added that the group helped with healing and increasing self-confidence as well as psychological and physical recovery. Although the group seemed homogeneous, one participant indicated that the social dynamics were still impacted by different personalities, cultures, and languages.

Most participants stated they would repeat the experience of participating in a singing group in this type of setting, which provided more freedom in learning and styles compared to a traditional choir, especially in classical choirs that are more "controlled." One stated, "I would do with pleasure this type of group again which allowed me to have a nice moment in music, while meeting people from diverse horizons and daily lives" and "I love to give back, I am happy to share, I liked the energy of the younger participants."

In terms of sustainability, the length of the project felt too short to affect the broader community, and the decreased attendance influenced motivation. People expressed that they wished to continue the group after the research was completed, as it was like " ... creating a community within the community." Some participants felt that their experiences in the group would serve them in their own communities. For instance, one woman participated in a women's group that composed songs together and saw opportunities open up due to her experience in the singing group.

\section{Language}

Language was an ongoing point of reference for everyone, as they could all relate to having cross-language experiences, from one perspective or another, and they were able to join together in laughter about this subject. Participants sounded comfortable singing in their own language and sounded unified despite different languages 
being sung simultaneously sometimes. The co-researchers helped make participants feel more comfortable by clarifying lyrics and language issues that arose. The group seemed concerned with the lyrics and the melody, with more complicated songs leading to more division and less togetherness at some moments. Some participants appreciated the mixture of languages. They mentioned it was interesting and positive to be able to sing in different languages even if they did not understand the full meaning. Others found it challenging to follow in another language or were less attracted by other languages. Singing lyrics, canons, and melodies felt agreeable for participants although it was challenging for others who were unfamiliar with the songs. As some of the songs were repeated from week to week for a certain period of time, one participant mentioned that at times it would have been nice to have had less repetition.

\section{Personal Experiences in Music Participation}

The group "opened up possibilities" and "gave a sense of mastery." The experience of the music itself brought about both positive and challenging reactions. The discovery of new repertoire, the sharing of each person's songs and their relationship to that particular song were viewed as positive outcomes. Music invited people to sing more, to disconnect from daily worries, and to be in the pleasure of the moment. One person mentioned that "singing with groups is something most powerful."

Another person mentioned that the "... voice is intimate and we are sharing it with others. We are accepting of the other person and know more about the person after sharing some songs." One woman mentioned that it is, "easier with music to give a sense of safety: we are all there at the same moment, doing the same thing with various stakes; feeling of belonging, having various ages; looking forward to see the results of this research." Beautiful musical moments moved some of the women.

Some songs were difficult to sing and some people would have preferred to have only listened to them. One participant started the project unsure about her ability to participate because of insecurity regarding her voice and pulmonary difficulties. She experienced some physical pain due to a health condition that did however improve with time.

\section{Group Termination}

The group had developed enough trust and cohesion to engage an improvisation within a song during the last session. There were some underlying feelings of uncertainty, but participants were pleasantly surprised. Perhaps the improvisation and the last-day effect had opened up some more musical playfulness. There was a moment when people looked up, in a beautiful section with soft harmonies, feeling safe in some repeated lyrics, looking at each other to collectively communicate when the ending was coming.

The group ended with participants sharing what they gained from the group, such as self-confidence, inclusivity, and freedom. They commented that the venue was amazing, comfortable, creative, and a safe space. Some participants expressed the desire to replicate the group in their own home community.

\section{Participants' Feedback}

The group members reported positive outcomes overall, but they also talked about aspects that they disliked and areas for improvement. As mentioned previously, the choice of songs and languages was at times challenging for some participants. In addition, one participant felt a separation sometimes between participants who had music background, in her words, the "music experts," and other participants who did not. Some said they learned better by ear, from hearing the songs, especially because they did not necessarily know musical vocabulary.

One participant felt that the social aspect was missing at times. For instance, when she arrived at the group and during breaks she did not always feel welcome while the co-researchers were preparing for the group. A few participants were disappointed that 
the size of the group diminished with time, and suggested that it might have been because of the winter, that the music was too challenging, or that they were intimidated to sing.

\section{Discussion}

\section{Community Music Therapy}

"The connection between music and community is the simple fact that music creates community" (Pavlicevic \& Ansdell, 2004, p. 28). This CoMT project, involving women from different generations and backgrounds, investigated the building of community through music therapy. It provided an opportunity to witness CoMT in action and is the beginning of an initiative that could be developed further.

According to Stige (2003), CoMT can be described as the "promotion of sociocultural and communal change through a participatory approach where music as ecology of performed relationships is used in non-clinical and inclusive settings" (p. 454). The goals for our particular group were to explore how a singing group could help develop community engagement and create a sense of belonging and personal accomplishment amongst various generations. Friendship can develop with people of various ages upon gaining a sense of equality as a co-researcher reported. The intergenerational experience between younger adults such as the co-researchers and the older participants is supported by research that shows the positive outcomes of working intergenerationally (Belgrave, 2012; Beynon et al., 2013).

All our actions were guided by CoMT principles, such as the cultural and social context of the project, democracy, openness, and promotion of well-being. We wanted to create a musical space that would foster social interactions and exchanges and ensure each individual's successful participation. Participants who decided to embark with the singing group did not know each other initially, yet in a very short time were able to develop early phases of community building. This project therefore differs slightly from some CoMT groups seen in the literature that have worked together and known each other for a longer period (Elefant, 2010; Stige, 2010). However, Stige and Aarø (2012) described CoMT projects as "collaborative endeavors whereby a range of agents get together (usually for a limited time period) with the aim of establishing new practices and inducing social change to the benefit of a location or group of people" (p. 205).

The timeline for this research was short-term. A longer project may have helped integrate further participants, and elaborate on and expand the singing group's impact to the broader community.

There were no public performances, which is not necessarily an essential condition for CoMT but is often associated with it. However, participants shared with one another their own song preferences and lived experience, and so we can say this work is performative in a sense. CoMT often involves a high level of involvement from participants, which was only partially accomplished here because of the short timeline of this project. With a long term CoMT group, there could be more opportunities to draw strengths from participants and develop leadership and individual initiatives.

Another challenge was the decreasing attendance level. This phenomenon was not investigated further as per the research consent form that stipulated that participants were free to leave the group without questions asked. Some participants volunteered the information that they had health issues and others went back to their country of origin having finished their studies. Future projects could consider more than 15 participants, to minimise the impact of drop outs.

\section{The Benefits of Singing Together}

Participants referred to enjoyable, positive community benefits: "mix of cultures, ages, the inclusion, the freedom, the ambiance, the pleasure, and a time for joy." Social benefits such as developing new relationships and sharing one's own musical network 
were observed (Bailey \& Davidson, 2003,, 2007; Clift \& Hancox, 2001; Cusicanqui \& Salmon, 2005; Li \& Southcott, 2012). Similarly to Young's (2009) study with adults living with cancer, participants enjoyed singing in "a safe and accepting environment... [they] discovered and explored [their] own unique voices" (p. 20). Vocalization and breathing exercises increased self-awareness. Musical participation also contributed to the beginnings of extra-musical community building. It was an opportunity to socialize, as people exchanged personal information, discussed music, and related on nonmusical material. The warm-up at the beginning of the group generated more full body movement from everyone and showed how the act of singing together is an embodied experience, which brought physical benefits (Parker, 1999; Stacy, Brittain, \& Kerr, 2002; Young, 2009). The voice is a very intimate instrument, so it was necessary to facilitate the creation of a safe space, to allow participants to contribute to the group without judgement and at their own pace.

\section{Sharing our Musical Inheritance}

The group provided a wide range of favourite songs from different social groups, geographic origins, languages, and generations. This diversity had both positive and challenging implications. Participants were introduced to new songs; however, some found them challenging to sing due to language barriers. The co-researchers were able to bring in additional songs that were more accessible. On the other hand, one of the goals of the group was to allow participants to share their own lived experience, so a balance between familiar songs and new songs had to be offered. Talmage et al. (2013) reported that musical preferences might be challenging when working with a mixed age group; the music therapist can invite and support the group to venture into other styles. Young (2009) also reported the importance of taking group members' cultural backgrounds into account and having them participate in music selections so that they could share messages and emotional content through their music choices. In the current project, some used music as a container for social interaction - such as for dancing or clapping together - and less as music for the sake of music. Music seemed to encapsulate the togetherness of the moment and supported the dancing. In some sessions, the level of energy felt high. The experience of togetherness in the music is interesting to witness in a group that did not know each other previously; it seems that music was a powerful means to connect, a phenomenon that DeNora (2002) qualified as social glue.

The bilingual context with both Francophones and Anglophones brought about some social identity discussions that emerged playfully and with various opinions asserted. Participants living in this city are used to this kind of interaction. There were some communication issues and misinterpretations amongst participants, co-researchers, and the primary researcher at times, possibly due to differences in individual identities such as language, region of origin, life experience, etc. Stige (2010) suggested tension and conflict could be by-products of collaboration or related to issues pertaining to identity (e.g. language of songs). Participants mentioned the pros and cons of having unilingual and multilingual groups, and using familiar songs versus discovering new songs. Stige (2010) documented a seniors' choir who alternated between new songs and known songs, songs that were harder and songs that came easily to participants, providing a suggested strategy for future CoMT singing groups.

\section{Music Therapists' Roles}

Music therapists are well situated to foster community building; they have developed specific musical and music therapy competencies to meet individuals where they are at, culturally and contextually. Like Stige (2010), the session leaders (music therapy student co-researchers) began with physical and vocal exercises, which were helpful beyond the session as they assisted participants in maintaining "physical and vocal capacity" (p. 247). This warm-up ritual was not necessarily specific to music therapy, but it is a current practice used by general singing groups and choirs. 
Music therapists are skilled in observing and analyzing participants' reactions and internal and external processes and responding appropriately. Music therapists also have the competence to address individuals' needs from a holistic perspective. This is important in a context where physical, psychological, cognitive and social needs might arise. Promoting health and preventing problems is not necessarily exclusive to "therapy" but is nevertheless part of music therapists' expertise. Stige and Aarø (2012) reiterated that the terminology of "therapy" is not always reflective of health prevention and promotion.

There are similarities between clinical singing groups conducted by music therapists (Talmage et al., 2013; Young, 2009) and non-clinical groups. Talmage et al. (2013) designed a detailed choral singing therapy protocol for working with adults living with neurological conditions. This protocol includes foundational principles such as recommendations for vocal exercises and songs, guidelines for choir membership and the therapeutic process, qualities of music therapists and music, and leadership responsibilities. Young (2009) also developed guidelines for community-based singing groups. Specific recommendations included the possibility that the group might not be a "therapy" context in itself. Instead, "the healing processes are meant to occur through the musical and social experiences" (p. 21). Young (2009) suggested in order to lead a group of this nature, music therapists need knowledge of vocal techniques, song repertoire, group dynamics, and clinical populations.

In our project, the co-researchers had some experience as leaders, music therapists, and musicians in previous groups and they demonstrated leadership by being in charge of warm-ups, teaching songs, and helping out with words, as well as during research meetings by contributing input and feedback to bring into sessions. They unanimously "loved co-leading." As Young (2009) mentioned, "the facilitator is a leader but not a conductor and provides support through full participation in the musical experiences" (p. 22). Talmage et al. (2013) stated, "When leading the group, the music therapist must balance individual and group needs, offer guidance and leadership, but also facilitate the members' ownership of the group" (p. 31). The co-researchers were music therapists trained to address individual and group needs and to foster leadership initiatives from participants. The group was supported through its phases of organic group development as participants began participating quietly with some hesitation, and gradually became more at ease with expressing themselves. Stige (2010) also noted that the role of a music therapist in this setting included that of conductor, instructor, motivator, mediator, and manager. The method was one of being simultaneously directive and attentive to the needs of the moment, ensuring that the members felt heard.

In the current study, using multiple music therapists as co-leaders led to both benefits and challenges. As mentioned previously, the co-researchers led the group interchangeably. One advantage of this decision was that in the absence of a particular coleader, the group could still take place. Various styles and music skills also enriched the experience. The co-researchers brought a live energy to the singing and to the group dynamic. They were skilled at responding to the music, not just making music, and according to one co-researcher, this helped participants to engage more in musicking as a collective, rather than as an individual activity.

On the other hand, it was challenging for the co-researchers to find the best leadership style for the singing group and for the research project itself. Although they enjoyed co-leading, the non-directive approach to leadership promoted by the primary researcher felt frustrating and awkward at times, as they were unsure of the expectations, and it was hard to determine whose responsibility it was to lead at certain moments. They also mentioned that doing research has technical requirements that could also be challenging. For instance they felt that the group could have been more effective with a longer duration. The repertoire was also demanding because of the diversity of preferences, lived experiences and languages of the participants. 


\section{Limitations}

The group could have represented further diversity. It was disappointing that recruitment did not reach teenagers from nearby schools and senior organizations, making the intergenerational age differentiation lower, with ages ranging from 20 to 65 . Although diverse amongst each other in various ways (i.e. language, country of birth, etc.), the group also consisted exclusively of women.

The project was also less geographically focused than previously hoped. This project aimed to look at community development in a low-income neighbourhood of a large city; however, only a few participants were from this area, three participants were from Europe and were in Canada completing an internship, and other participants resided in other areas of the city. The co-researchers tried to take into considerations the broader "communities" within this new created group. Bridging with the Art Studio Community Center was a way to connect with the local area, as some participants came from that center.

Working with a non-clinical population in a context of music therapy is an avenue that needs further research and attention in Canada. This research could expand and articulate a diversity of practices in CoMT.

We cannot generalize findings from the project and assert that the broader community benefited from the project. However, individuals may have brought what they gained from the group back to their own community. Short-term follow up was not pursued, for example in the case where someone missed a session or stopped coming. The primary researcher respected the research consent form stating that there would be no questions asked, to diminish any pressure or coercion to participate to the research. No long-term follow-up concerning community building was done after the sessions except the post-group interviews. The group duration may have been too short to witness advanced community building outside of the singing group. Unfortunately, funding did not allow pursuing the project further at that time. A future research project could gather more data on the longitudinal effect of the group and examine how the project influenced the participants' community engagement and life over time. The decrease in attendance, as mentioned earlier, was also a limitation to witnessing more community building.

Another limitation was that the primary researcher conducted pre and post group interviews for logistical reasons. This fact might have influenced responses from participants and co-researchers, who might have felt the need to give the "right" answer in order to please the primary researcher, and therefore did not express feelings of dissatisfaction.

\section{Further Considerations and Research}

In essence, an intergenerational singing group in the community setting must stay simple, inclusive, flexible, joyful, and pleasurable, for the benefits of all. Future research could focus on the dynamics of leading and co-leading sessions, the specific impact of repertoire, and psychosocial impacts on attendance. We noted some challenges with attendance, musical choices, and collaborative leadership. Further research could examine the following questions:

- How do we attract participants to a CoMT project;

- How do we optimize the integration of different musical choices in order to make the group accessible and inclusive; and

- What type of co-leadership is the most suitable for this type of group?

\section{Conclusion}

We created a community music therapy project that offered participants the opportunity to share their identities through music and community. The work was based on principles targeted by CoMT pioneers such as social-democracy, inclusion, individual and 
group expression, and community outreach (Ansdell, 2002; Pavlicevic \& Ansdell, 2004; Ruud, 2004; Stige, 2003; Stige \& Aarø, 2012; Stige, Ansdell, Elefant, \& Pavlicevic, 2010). There are many potential research projects that could help expand the benefits of CoMT singing groups and bring forward individual and community strengths with non-clinical populations or with specific social groups. Research is still limited and "empirical grounding and theory development are vital factors influencing Community music therapy practice. Practice evolves locally, informed by values, local knowledge, and social-musical processes" (Stige \& Aarø, 2012, p. 235). As Daykin (2007) mentioned, "The benefits of the arts are constructed across a broad continuum that has, at one end, individual health and wellbeing and, at the other, social and cultural impacts... social wellbeing is addressed through community participation, to which the arts can contribute" (p. 84). It is the authors' hope that more CoMT research initiatives will emerge in Canada and abroad, given the multiple benefits of group singing.

\section{Authors' notes}

We would like to thank our participants who generously agreed to be part of the research and in doing so have made an important contribution to the field. We extend our thanks to Janis Timm Bottos, Associate Professor and art therapist, for her support and for lending us the art studio community center. We thank Concordia University for the grant Seed Funding (Individual) Program.

\section{References}

Ansdell, G. (2004). Introduction 'The ripple effect'. In M. Pavlicevic \& G. Ansdell (Eds.), Community music therapy (pp. 15-31). London, England: Jessica Kingsley.

Ansdell, G. (2002). Community music therapy and the winds of change: A discussion paper. In C. B. Kenny \& B. Stige (Eds.), Contemporary voices in music therapy: Communication, culture, and community (pp. 109-142). Oslo, Norway: Unipub Forlag. https://doi.org/10.15845/ voices.v2i2.83.

Ayala, J., Hewson, J. A., Bray, D., Jones, G., \& Hartley, D. (2007). Intergenerational programs: Perspectives of service providers in one Canadian city. Journal of Intergenerational Relationships, 5(2), 45-60, https://doi.org/10.1300/J194v05n02_04.

Bailey, A., \& Davidson, J. (2007). Psychological and physical benefits of participation in vocal performance. In J. Edwards (Ed.), Music: Promoting health and creating community in healthcare contexts (pp. 52-63). Newcastle, UK: Cambridge Scholars Publishing. https://doi.org/10.1080/08098130309478070.

Bailey, B. A., \& Davison, J. W. (2003). Amateur group singing as a therapeutic instrument. The Nordic Journal of Music Therapy, 12, 18-33, https://doi.org/10.1080/08098130309478070.

Baines, S. A. (2003). Consumer-directed and partnered community mental health music therapy program: Program development and evaluation. Voices: A World Forum for Music Therapy, 3(3), https://doi.org/10.15845/voices.v3i3.137.

Batt-Rawden, K., Trythall, S., \& DeNora, T. (2007). Health musicking as cultural inclusion. In J. Edwards (Ed.), Music: Promoting health and creating community in healthcare contexts (pp. 64-82). Newcastle, UK: Cambridge Scholars Publishing.

Belgrave, M. (2012). Implementing music therapy-based intergenerational programs in the community. The International Journal of the Arts in Society, 6(6), 1-10, https://doi.org/ 10.18848/1833-1866/CGP/v06i06/36109.

Beynon, C., Heydon, R., O'Neill, S., Zhang, Z., \& Cocker, W. (2013). Straining to hear the singing: Toward an understanding of successful intergenerational singing curriculum. Journal of Intergenerational Relationships, 11(2), 176-189, https://doi.org/10.1080/ 15350770.2013 .782747$.

Bird, N. (1998). I'm dangerous with sound: A performance project of sound, poetry and movement. Open University, BC, Canada. Unpublished master's thesis. 
Clift, S., \& Hancox, G. (2001). The perceived benefits of singing: Findings from preliminary surveys of a University College Choral Society. Journal of the Royal Society for the Promotion of Health, 121(4), 248-256, https://doi.org/10.1177/146642400112100409.

Conway, C., \& Hodgman, T. M. (2008). College and community choir member experiences in a collaborative intergenerational performance project. Journal of Research in Music Education, 56, 220-237, https://doi.org/10.1177/0022429408327297.

Curtis, S. L. (2015). Profile of community music therapists in North America: A survey. Voices: A World Forum for Music Therapy, 15(1), https://doi.org/10.15845/voices.v1i1.811.

Curtis, S. L. (2012). Music therapy and social justice: A personal journey. The Arts in Psychotherapy, 39, 209-213, https://doi.org/10.1016/j.aip.2011.12.004.

Curtis, S., \& Vaillancourt, G. (2012). The children's right to music project. Voices: A World Forum for Music Therapy, 12(3), https://doi.org/10.15845/voices.v12i3.676.

Curtis, S. L., \& Mercado, C. S. (2004). Community music therapy for citizens with developmental disabilities. Voices: A World Forum for Music Therapy, 4(3), https://doi.org/ 10.15845/voices.v4i3.185.

Cusicanqui, M., \& Salmon, R. (2005). Senoirs, small fry, \& song. Journal of Gerontological Social Work, 44(1-2), 189-210, https://doi.org/10.1300/J083v44n01_11.

Darrow, A., Johnson, T., \& Meeker Miller, A. (2001). The effect of an intergenerational choir on audience members' attitudinal statements toward teens and older persons. International Journal of Music Education, 38, 43-50, https://doi.org/10.1177/025576140103800105.

Daykin, N. (2007). Music: Promoting health and creating community in healthcare contexts. Newcastle, UK: Cambridge Scholars Publishing. pp. 83-104.

DeNora, T. (2002). Music in everyday life. Cambridge: University Press.

Elefant, C. (2010). Giving voice: Participatory action research with a marginalized group. In B. Stige, G. Ansdell, C. Elefant, \& M. Pavlicevic (Eds.), Where music helps: Community music therapy in action and reflection (pp. 199-215). Surrey, England: Ashgate.

Fogg, L., \& Talmage, A. (2011). The CeleBRation Choir: Establishing community group choral singing for people living with neurological conditions. Psychomusicology: Music, Mind \& Brain, 21, 264-267, https://doi.org/10.1037/h0094030.

Li, S., \& Southcott, J. (2012). A place for singing: Active music engagement by older Chinese Australians. International Journal of Community Music, 5(1), 59-78, https://doi.org/10.1386/ ijcm.5.1.59_1.

Neuman, W. L. (2011). Social research methods: Qualitative and quantitative approaches. Whitewater, WI: University of Wisconsin.

Oosthuizen, H., Fouché, S., \& Torrance, K. (2007). Collaborative work: Negotiations between music therapists and community musicians in the development of a South African community music therapy project. Voices: A World Forum for Music Therapy, 7(3), https://voices.no/index.php/voices/article/view/546/407.

Parker, B. (1999). «Singing your worries away». Mastersingers, 32.

Pavlicevic, M., \& Ansdell, G. (2004). Introduction 'The ripple effect'. In M. Pavlicevic \& G. Ansdell (Eds.), Community music therapy (pp. 15-31). London, England: Jessica Kingsley.

Ruud, E. (2004, November 22). Defining community music therapy [Msg 4]. Message posted to http://www.voices.no/discussions/discm4_04.html

Sattler, G. (2013). Playing outside the generational square: The intergenerational impact of adult group music learning activities on the broader community. International Journal of Community Music, 6(3), 311-320, https://doi.org/10.1386/ijcm.6.3.311_1.

Snow, S., Snow, S., \& D’Amico, M. (2008). Interdisciplinary research through Community music therapy and performance ethnography. Canadian Journal of Music Therapy, 14(1), 30-46.

Stacy, R., Brittain, K., \& Kerr, S. (2002). Singing for health: An exploration of the issues. Health Education, 102(4), 156-162, https://doi.org/10.1108/09654280210434228. 
Stewart, D. (2004). Narratives in a new key: Transformational contexts in music therapy. In M. Pavlicevic \& G. Ansdell (Eds.), Community music therapy (pp. 281-297). London, England: Jessica Kingsley.

Stige, B. (2010). Action- caring for music: The senior choir in Sadane, Norway. In B. Stige, G. Ansdell, C. Elefant, \& M. Pavlicevic (Eds.), Where music helps: Community music therapy in action and reflection (pp. 245-251). Surrey, England: Ashgate.

Stige, B. (2003). Elaborations toward a notion of community music therapy. Oslo, Norway: Unipub. Doctoral dissertation.

Stige, B., \& Aarø, L. E. (2012). Invitation to community music therapy. New York, NY: Routledge.

Stige, B., Ansdell, G., \& Elefant, M. (Eds.). (2010). Where Music Helps: Community Music Therapy in Action and Reflection. London, England: Ashgate.

Talmage, A., Ludlam, S., Leão, S. H. S., Fogg-Rogers, L., \& Purdy, S. C. (2013). Leading the CeleBRation Choir: The choral singing therapy protocol and the role of the music therapist in a social singing group for adults with neurological conditions. New Zealand Journal of Music Therapy, 11, 7-50.

Vaillancourt, G. (2009). Mentoring apprentice music therapists for peace and social justice through community music therapy: An arts-based study. UMI Dissertation Publishing. Doctoral Dissertation.

Vaillancourt, G. (2012). Music therapy: A community approach to social justice. The Arts in Psychotherapy, 39(1), 173-178, https://doi.org/10.1016/j.aip.2011.12.011.

Young, L. (2009). The potential health benefits of community based singing groups for adults with cancer. Canadian Journal of Music, 15(1), 11-27.

Zharinova-Sanderson, O. (2004). Promoting integration and socio-cultural change: Community music therapy with traumatised refugees in Berlin. In M. Pavlicevic \& G. Ansdell (Eds.), Community music therapy (pp. 233-248). Philadelphia, PA: Jessica Kingsley. 